\title{
O narcisismo e a relação com a alteridade nas psicoses sob os olhares de Freud, Tausk e Federn
}

\author{
Narcissism and the relation to otherness \\ in psychoses from the points of view of \\ Freud, Tausk and Federn
}

Silvia Marini*1

Viviana Carola Velasco Martinez*2

Este trabalho tem como objetivo analisar a relação ou o lugar da alteridade na dinâmica psíquica das psicoses a partir das ideias de Freud, sobretudo aquelas vinculadas ao conceito de narcisismo, e que influenciaram as teorias de Tausk e Federn, autores que se aventuraram no campo do estudo e tratamento das psicoses no momento em que o próprio pai da psicanálise dizia ser impossivel. Deste estudo podemos concluir que a alteridade concreta se fez e se faz presente no psiquismo psicótico para os três autores, de modo que o conflito e o processo terapêutico implicam a existência e a relação com o outro.

Palavras-chave: Psicanálise, psicose, narcisismo, alteridade

*1 Centro Universitário Metropolitano de Maringá - Unifamma (Maringá, PR, Brasil).

*2 Universidade Estadual de Maringá (Maringá, PR, Brasil). 


\section{ARTIGOS}

Este trabalho tem como objetivo analisar, a partir do conceito de narcisismo proposto por Freud (1914/2010a), a relação ou o lugar da alteridade, ou seja, do outro na dinâmica psíquica das psicoses. ${ }^{1}$ Para isso, recorremos às ideias do próprio Freud acerca das psicoses, sobretudo aquelas elaboradas a partir de 1914. Isso porque é nesse período que as teorizações sobre o conceito de narcisismo transformaram e ampliaram as ideias psicanalíticas sobre o eu e influenciaram de modo determinante Tausk e Federn, autores contemporâneos de Freud, que se aventuraram no campo do estudo e tratamento das psicoses no momento em que o próprio pai da psicanálise dizia não ser possível.

Muito embora não se reconheça a existência de uma teoria freudiana sobre as psicoses, a descoberta do conceito de narcisismo foi fundamental para a compreensão psicanalítica dessas patologias. Freud (1914/2010a), no texto "Introdução ao narcisismo", a partir da análise da megalomania, sintoma encontrado sobretudo na paranoia, utilizou o conceito para nomear o estado psíquico no qual o investimento libidinal se restringe ao Eu. Para o autor, essa condição psíquica inicial da libido é universal e caracteriza o narcisismo primário, ou seja, o estado no qual a libido não encontrou, ainda, o caminho dos objetos e da realidade externa e, por isso, toma o Eu como único objeto de investimento e satisfação.

Esse estado de investimento libidinal é caracterizado como um estágio de desenvolvimento da sexualidade localizado entre o autoerotismo e o amor objetal. Essa discussão já pode ser

${ }^{1} \mathrm{O}$ interesse pela alteridade, pelo lugar do outro, na dinâmica psíquica das psicoses é resultado da nossa pesquisa de doutorado A contratransferência no cuidado do paciente psicótico: do horror e inveja à indiferença, iniciada em 2015 no Programa de Pós-graduação em Psicologia da Universidade Estadual de Maringá. Assim, este trabalho representa alguns resultados da pesquisa. 
encontrada na seção III - Sobre o mecanismo da paranoia do Caso Schreber, onde Freud (1911/2015) afirma que o narcisismo

consiste no fato de o indivíduo em desenvolvimento, que unificou seus instintos sexuais que agem de forma autoerótica, a fim de obter um objeto de amor, primeiramente toma a si mesmo, a seu próprio corpo, como objeto de amor, antes de passar à escolha de uma outra pessoa como objeto. (p. 52)

Essa fase mediadora entre o autoerotismo e a escolha objetal é considerada etapa universal de todo o desenvolvimento psicossexual. Assim, o que caracteriza a paranoia e a esquizofrenia é o retorno a esse estado - daí o conceito de narcisismo secundário - como processo defensivo frente à impossibilidade do Eu em obter satisfação libidinal nos objetos e na realidade externa.

Essa compreensão teórica, Freud (1914/2010a) alcançou graças à análise das neuroses de transferência em relação à transferência nas psicoses ou neuroses narcísicas. Segundo ele, nas neuroses o investimento objetal da libido se mantém, mesmo em face das alterações do Eu e de sua relação com a realidade. Já as psicoses seriam caracterizadas pela ausência total de objetos externos, mesmo na fantasia. É possível encontrar nesse texto, portanto, uma clara distinção entre essas psicopatologias a partir da presença ou ausência da condição psíquica de transferência e que pressupõe a manutenção das relações objetais, ou seja, o investimento e o reconhecimento da alteridade.

Assim, nas psicoses, a retirada da libido objetal e o reinvestimento no Eu promovem o aumento do amor próprio e a regressão ao estado primitivo de onipotência e independência da relação com os objetos externos e suas representações para a satisfação do desejo, o que Freud (1914/2010a) denomina de "um estado psíquico bem-aventurado, uma posição libidinal inatacável..." (p. 23).

Assim, a partir das considerações realizadas até aqui, as psicoses na teoria freudiana aparecem descritas em seus sintomas, conflitos e relações com a realidade externa, como expressões do funcionamento psíquico regredido a estágios primitivos do desenvolvimento psicossexual e de satisfação do desejo. O narcisismo secundário dessas patologias parece ser o exemplo máximo da busca pelo estado de onipotência vivenciada durante a infância, marcado pela libido restrita ao Eu e pela ausência total de objetos externos e, consequentemente, pela independência deles no processo de satisfação pulsional.

$\mathrm{O} \mathrm{Eu}$ e sua relação com o desejo para a compreensão dos processos patológicos ganha destaque ainda maior no interior da segunda tópica 


\section{ARTIGOS}

freudiana. Para Simanke (2009), a problemática que orientará Freud nesse novo momento é a compreensão do mecanismo de defesa empregado nas psicoses denominado de renegação (Verleugnung). ${ }^{2}$ Assim, nas psicoses, o

${ }^{2} \mathrm{Ou}$ Verwerfung? Há na literatura psicanalítica uma extensa discussão acerca do mecanismo de defesa específico das psicoses, uma vez que Freud utilizará em alguns textos, inclusive para se referir a mecanismos psíquicos mais gerais, o conceito de renegação (Verleugnung) e em outros o conceito de rejeição (Verwerfung). Laplanche e Pontalis (1988) se referem a outros termos que, em Freud, aparecem próximos à Verwerfung, como Ablehnen, Aufheben e Verleugnung.

Será Lacan quem proporá uma especificidade para a Verwerfung — traduzida como forclusão (do Nome-do-Pai) -, associando-a fortemente às psicoses, diferenciando-a da Verleugnung, das perversões e, ainda, da Verdrängung, das neuroses, mecanismos de defesas estes próprios de cada estrutura. Contudo, é muito interessante o comentário de Laplanche e Pontalis (1988) a esse respeito: "Podemos verificar, limitando-nos ao ponto de vista terminológico, que o uso do termo Verwerfung não abrange sempre a ideia expressa por forclusão e que, inversamente, outras formas freudianas designam o que Lacan procura evidenciar" (p. 573). Por outro lado, Lacan (citado por Hanns, 1996) destaca pelo menos dois textos em que Freud efetivamente vai discriminar ambos os mecanismos de defesa. No Homem dos Lobos, onde aparece o verbo verwerfen, e no Fetichismo, onde encontramos a Verleugnung. Mas, mesmo assim, a reflexão de Freud em torno da Verleugnung do fetichismo, afirmam Laplanche e Pontalis (1988) "indica explicitamente que esse mecanismo cria um parentesco entre esta perversão e a psicose (p. 574, 7, 8a). A recusa oposta pela criança, pelo fetichista, pelo psicótico, a esta 'realidade' que seria a ausência de pênis na mulher é concebida como uma recusa a admitir a própria 'percepção' e a fortiori a tirar a respectiva consequência, quer dizer, a 'teoria sexual infantil' da castração" (p. 574). Para Penot (apud Mijolla, 2005), a forclusão que, para Lacan, impede que uma representação desempenhe algum papel simbólico, "pode intervir, por outro lado, de uma forma relativa ou paradoxal ao inscrever-se na tópica particular do Eu clivado, realizando nesse caso uma rejeição-negação característica das chamadas estruturas perversas. Resta o fato de que, em graus diversos, uma tal rejeição à margem da simbolização constitui um profundo entrave para que a representação mental envolvida possa participar como elementos no jogo simbólico que constitui a a vida mental e fantasmática do sujeito" (p. 1595).

Mais tarde, continuam Laplanche e Pontalis (1988), em 1938, Freud vai se referir a "dois modos de defesa: 'repelir uma exigência pulsional do mundo interior' e 'recusar um fragmento do mundo exterior real' (8b)" (p. 574), retomando de certa forma a defesa psicótica proposta, em 1894, em que "O Ego separa-se da representação insuportável, mas esta está indissoluvelmente ligada a um fragmento da realidade e, realizando esta ação, o ego separou-se também totalmente ou parcialmente da realidade (2b)." (p. 574) 
conflito se dá entre o Eu e a realidade externa, pois à medida que a realidade externa impede a satisfação pulsional ela é renegada e deixa de ter influência sobre o Eu (Freud, 1924/2010d).

Mas a qual parte da realidade Freud se refere? Ou, ainda, qual dado da realidade pode ter tamanho efeito sobre o Eu e a satisfação pulsional? A resposta pode ser encontrada na castração, pois nas psicoses a castração não leva à repressão, como na neurose, e sim à renegação (Verleugnung) da realidade e à construção de uma nova realidade.

O Eu cria um novo mundo exterior e interior, e não há dúvida quanto a dois fatos: de que esse novo mundo é edificado conforme os impulsos de desejo do $I d$, e de que o motivo dessa ruptura com o mundo exterior é uma difícil, aparentemente intolerável, frustração do desejo por parte da realidade. (Freud, 1924/2010c, p. 161; grifo nosso)

No texto "A perda da realidade na neurose e na psicose", Freud (1924/2010d) caracteriza as psicoses em dois estágios: “o primeiro arrancaria o $\mathrm{Eu}$ da realidade (...), enquanto o segundo tenderia a corrigir o dano e restabeleceria a relação com a realidade à custa do Eu" (p. 195). Esse segundo estágio, assim como na neurose, objetiva uma compensação do Id, mas não por meio da sua restrição e do recalcamento (Verdrängung), mas por meio da criação de uma nova realidade adequada à satisfação das pulsões e da busca do restabelecimento dos vínculos objetais. Assim, "Na psicose, a remodelação da realidade acontece nos precipitados psíquicos das relações até então mantidas com ela, ou seja, nos traços mnemônicos, ideias e juízos que dela foram adquiridos até então, e pelos quais ela era representada na vida psíquica" (p. 196).

As psicoses, para a teoria freudiana, são patologias do Eu marcadas pelo domínio do narcisismo, da onipotência e da primazia do desejo diante da realidade externa e dos objetos, o que num primeiro momento significa o desinvestimento objetal, mas, num segundo, o reinvestimento das inscrições psíquicas desses mesmos objetos no processo de reconstrução da realidade interna e externa para a satisfação pulsional. Assim, os sintomas passam a ser considerados tentativas do eu para reaver os objetos e, portanto, de cura, e a alteridade é recolocada como fundamental. 


\section{ARTIGOS}

\section{Tausk e o Aparelho de influenciar das psicoses}

Tausk foi discípulo de Freud e um dos poucos, na época, a utilizar a psicanálise na compreensão e tratamento das psicoses. Ao construir sua teorização a partir da análise de um sintoma delirante, o aparelho de influenciar, ele nos oferece elementos para compreender o lugar do desejo e da alteridade no interior da dinâmica psíquica das psicoses.

No texto "Da Gênese do 'Aparelho de Influenciar' no Curso da Esquizofrenia", publicado em 1919, Tausk (1919/1990) chama a atenção sobre o gradativo estranhamento que o psicótico apresenta de si, do seu corpo, das suas sensações e do seu desejo. E, por não tolerar sua própria excitação pulsional, constrói o aparelho de influenciar que, ao ser projetado no mundo exterior e controlado por um inimigo, o subjuga e persegue. Ou seja, aqui também o psicótico é apresentado sob o domínio do desejo, que, vindo de fora, o domina.

Nessa dinâmica, as relações que estabelece e a satisfação do desejo são mediadas pelo aparelho, de modo que as pessoas com as quais se relacionam estão em dois lugares: ou controlam a máquina ou são controladas e submetidas por ela. Ambos os lugares caracterizam o perigo que as relações objetais representam para os psicóticos, posto que são elas que estimulam o desejo, ameaçam o estado de narcisismo e, com isso, promovem o conflito psíquico.

Tausk (1919/1990) descreveu as dificuldades terapêuticas enfrentadas por ele no tratamento das psicoses, à medida que era colocado em algum desses lugares, o que, por sua vez, dificultava o estabelecimento do vínculo de confiança. Ao descrever um caso em seu texto, ele se refere à evolução dos sintomas: "Não pude saber mais pela própria doente. Quando a vi pela terceira vez, mostrou-se reticente e afirmou que eu também estava sob a influência da máquina, sendo-lhe hostil, e que eu não podia mais compreendê-la" (p. 50).

Segundo ele, as pessoas mais distantes, ou seja, médicos, cuidadores, conhecidos, pretendentes, são, geralmente, aquelas que gradativamente são postas no lugar de manipuladoras da máquina. Já as pessoas mais próximas, pais e irmãos, são manipulados pelo aparelho, assim como o próprio paciente, posto que os vínculos primitivos que representam se caracterizam pela identificação e antecedem o vínculo marcado pelo investimento objetal. É o vínculo propriamente objetal que ameaça os psicóticos e o estádio narcísico da libido ao qual se fixaram. Assim, a partir dessa perspectiva, podemos conceber que a alteridade no interior da dinâmica psíquica das psicoses está no lugar de inimiga que excita e persegue. 
Destaca-se, também, na teoria de Tausk (1919/1990), o papel dos órgãos e do corpo na comunicação e expressão do desejo e do conflito. Esse reconhecimento foi realizado pelo próprio Freud (1915/2010b) que, na última sessão do texto "O inconsciente", cita um dos casos analisados por Tausk para denominar a fala concreta do esquizofrênico como fala dos órgãos. Trata-se do caso da jovem que após uma discussão com o namorado queixa-se de que os olhos estão tortos. Isso porque é na vivência da excitação e das transformações corporais resultantes do retorno ao narcisismo que os sintomas se expressam.

Vamos, então, para a análise do que Tausk (1919/1990) denomina de aparelho de influenciar. Para ele, o aparelho tem natureza mística e, por isso, impossível de ser explicada em sua constituição e funcionamento por meio da aproximação com as invenções humanas. Embora alguns pacientes tentem lhe atribuir botões e alavancas e o imaginem ligados aos seus corpos por fios, em linhas gerais é um aparelho misterioso e poderoso. Poderoso porque encarna o desejo e, misterioso, pois comunica o desejo intolerável do outro e pelo outro.

Segundo o autor, se a constituição e o funcionamento são desconhecidos, os efeitos do aparelho de influenciar são descritos em detalhes pelos pacientes. São eles: apresentação de imagens aos doentes; produção e furto de sentimentos e pensamentos; produção de ações motoras como ereções e poluções; produção de sensações, algumas estranhas e outras sentidas como correntes elétricas, magnéticas, raios X ou correntes atmosféricas, e produção de fenômenos somáticos (furúnculos, erupções cutâneas, ereções, entre outros).

Seu objetivo geral é perseguir e, por isso, como já dito, sua manipulação é atribuída a um inimigo. Embora nem todos os pacientes atribuam à existência de um aparelho suas alterações corporais, sensoriais e perceptivas que vivenciam, "não há dúvidas de que as reclamações de doentes que não apelam para a intervenção de um aparelho, precedem a aparição do sintoma do aparelho de influenciar: o 'aparelho' é uma manifestação mais tardia da doença” (Tausk, 1919/1990, p. 42).

Para o autor, o aparelho, como máquina, é um sintoma que simbolicamente, e isso ele busca em Freud, corresponde aos órgãos sexuais dos pacientes. "Os esquizofrênicos, queixando-se de que este aparelho produz ereções, subtrai o esperma, enfraquece-lhes a virilidade, apenas reforçam esta suposição" (p. 48).

Essas características do aparelho podem ser compreendidas à luz da análise da perda dos limites do ego. Tal sintoma se torna acessível pela queixa inicial dos esquizofrênicos de que todos sabem o que se passa na sua 


\section{ARTIGOS}

cabeça, ou seja, conhecem seus pensamentos como se não houvesse limites que os impedissem de se espalhar pelo mundo. Para Tausk (1919/1990), isso significa que o doente perde a consciência de ser uma unidade psíquica e, com ela, os limites que o separam do mundo externo e dos objetos.

Contudo, nos diz o autor, essa percepção psíquica não é exclusiva dos esquizofrênicos, mas faz parte da história constitucional do ego infantil, ou seja, do estádio de narcisismo. O início do ego coincide com a descoberta dos objetos e do mundo exterior e, antes de sua constituição, a relação estabelecida entre o psiquismo e esses mesmos objetos é de identificação. É por meio da identificação que o ego busca se apropriar das coisas que excitam os órgãos dos sentidos. A perda dos limites do Eu diz respeito à regressão a esse estádio infantil da libido.

Assim, no caso dos esquizofrênicos, a libido não encontrou caminho para o mundo externo e permaneceu vinculada às identificações realizadas e a si mesmos, "Esses doentes são, eles próprios, o que lhes agrada no mundo exterior; é por isso que não encontraram o caminho do mundo exterior, a posição de objeto..." (p. 56). As relações e os vínculos que ameaçam esse estado são vivenciadas como extremamente perigosas ao Eu.

Por isso, o autor descreve essa posição libidinal narcísica como anobjetal, já que objeto e ego se confundem. Intelectualmente, esse estádio representa o momento em que todas as estimulações são concebidas como endógenas, já que não existe distância espacial e temporal entre objeto e percepção.

Portanto, assim como Freud, Tausk (1919/1990) encontra na fixação e, posteriormente, no retorno da pulsão ao estádio narcisista da libido, a explicação para as psicoses, o que produz uma inibição da libido, que "corresponde a uma inibição intelectual que se manifesta sob a forma de uma perturbação do julgamento ou loucura" (p. 58). Ele, ainda, deriva dessa mesma inibição a angústia característica desses quadros.

O início da doença se dá com o retorno do investimento libidinal no ego e o excesso pulsional vivenciado como estimulação corporal vinda de fora, e estranha ao Eu. "Esse período deve coincidir com o estádio evolutivo no decorrer do qual a descoberta do objeto se passava ao nível do próprio corpo, sendo este, então, ainda considerado como mundo exterior" (p. 61; grifos do autor). Daí o estranhamento que as próprias sensações corporais e excitações psíquicas representam.

Para o autor, a condição de projetar no mundo externo as percepções e sensações é o principal recurso defensivo, utilizado pelos psicóticos, contra o 
desejo proibido. O lugar do desejo é no mundo externo e nos objetos que dele fazem parte. $\mathrm{O}$ aparelho, manipulado por outrem, é que excita, que persegue, que transforma, que enlouquece e, ainda, que promove a alienação do desejo. Assim, podemos concluir que, nesta teoria, os sintomas dos psicóticos e sua comunicação dirigida ao mundo e às pessoas transfere o sexual não tolerado, marcado pelo excesso e pela persecutoriedade. É na alteridade que se encontra o desejo alienado.

Se para Freud o retorno ao narcisismo pressupõe a recusa da realidade externa e do objeto, para Tausk esse mesmo retorno implica o perigo e persecutoriedade do objeto que incita o desejo.

\section{Federn e o fracasso do eu nas psicoses}

Assim como Tausk, Federn partiu de um sintoma psicótico, a saber, o estranhamento, para analisar e propor uma teorização sobre as psicoses, o que faz em seu livro La psychologie du moi et les psychoses (Federn, 1952/1979), sem tradução para o português.

Para o autor, a existência do Eu depende do investimento libidinal tanto na sua dimensão psíquica quanto corporal. $\mathrm{Na}$ sua definição descritiva, o Eu se configura como a continuidade psíquica duradoura do corpo e da mente de um indivíduo sob a perspectiva de espaço, tempo e causalidade. Na definição fenomenológica (subjetivamente descrita), o Eu é sentido e conhecido como essa continuidade duradoura que é apreendida e sentida como unidade. Por fim, na definição metapsicológica, o Eu se apresenta como um estado de investimento libidinal de certos conteúdos e funções corporais e mentais interligadas.

É na dimensão do sentimento do Eu, ou seja, na perspectiva fenomenológica da sua existência, que o autor localiza a explicação para o sintoma de estranheza característico das psicoses. Assim, ele define o sentimento do Eu como

a sensação constante de si próprio, a autopercepção de si mesmo. Essa autoexperiência é uma unidade permanente mas diversificada; não é uma abstração, mas uma realidade. É uma entidade que se relaciona com a continuidade da pessoa em relação ao tempo, espaço e causalidade. Por ser objetivamente reconhecido é constantemente sentido e percebido subjetivamente. Em outras palavras, temos um sentimento duradouro e 


\section{ARTIGOS}

o conhecimento do fato que o nosso ser é contínuo. (Federn, 1952/1979, p. 114; tradução livre). ${ }^{3}$

O sentimento de estranheza presente nas psicoses, porém não exclusivo delas, se caracteriza por falhas no sentimento do Eu e a consequente perda de suas funções. Muitas vezes o corpo, os sentimentos e, principalmente, a realidade externa são percebidos como indiferentes ou estranhos. Isso porque o Eu é a dimensão psíquica que mantém contato com a realidade a partir de suas fronteiras, processo que se desenvolve gradualmente.

Inicialmente, ou seja, no início da vida psíquica, as fronteiras do Eu são pequenas e se relacionam sobretudo aos conteúdos mentais e às percepções vindas de dentro. Contudo, à medida que o desenvolvimento psicossexual avança e as zonas erógenas se apresentam como importantes fontes de excitação, os limites dessas fronteiras se expandem, processo que se intensifica a partir do contato com o mundo externo e do investimento libidinal nos objetos. É do contato com a realidade que o Eu se constitui e se transforma gradativamente em um Eu adulto.

Por isso, o autor divide a dimensão subjetiva do Eu em sentimento corpóreo e sentimento mental, e consequentemente pressupõe a existência de limites corporais e mentais. Desse modo, o que vem do exterior e faz uma colisão com a borda do ego mental e do ego corporal tem uma realidade sólida. Essa realidade é emocionalmente autoevidente e não precisa de mais verificação. O "teste da realidade" só é possível porque durante o experimento foram estabelecidos novos limites do ego e as mesmas impressões vindas do exterior já não se chocam.

As estimulações externas que se chocam com apenas uma das dimensões do limite do Eu, ou seja, a dimensão mental ou corporal, são percebidas como bizarras, já que a apreensão e sensação dependem da estimulação de ambas as fronteiras. Por isso, o relacionamento com o

3 'La sensation constamment présente de sa propre personne, c'est la perception propre que le moi a de lui-même... Cette auto-expérience est une entité permanente bien que diverse; elle n'est pas une abstraction mais une réalité. C'est une entité qui a trait à la continuité de la personne eu égard au temps, à l'espace, et à la causalité. Elle peut être reconnue objectivement et elle est constamment sentie et perçue subjectivement. En d'autres termes nous possédons un sentiment et une connaissance durables du fait que notre moi est continu" (Federn, 1952/1979, p. 114). 
mundo exterior é fundamental, já que é a extensão do estado de investimento libidinal que constitui o Eu, processo variável, que possibilita a percepção e sensação conscientes.

Para o autor, todas as psicoses e neuroses são iniciadas com o sentimento de estranheza, causado pelo desinvestimento libidinal de algum limite do Eu. Isso porque, diante de situações traumáticas, "o sentimento do eu é capaz de se fixar ou regredir a um estágio anterior tanto em termos de qualidade quanto de extensão" (p. 121; tradução livre). ${ }^{4}$

Segundo o autor, para Freud, o sentimento do Eu é resultado do narcisismo primário, caracterizado pela ausência de objetos e pelo investimento libidinal no próprio Eu. Para ele, contudo, esse sentimento é resultado do narcisismo intermediário, já que ele se constitui gradativamente à medida que as fronteiras do Eu são investidas, o que acontece a partir do contato com a realidade externa e com os objetos. $\mathrm{O}$ narcisismo resultante da retirada do investimento libidinal dos objetos que atingiram o limite do Eu, por sua vez, Federn (1952/1979) denomina de narcisismo reflexivo.

É no âmbito do Eu corporal que o autor localiza a função de 308 perceber os objetos que, a partir disso, serão apreendidos pelo Eu mental. Por isso, os casos de despersonalização podem ser compreendidos a partir de variações de investimento nos limites do Eu corporal. Assim, quando a privação do objeto ocorre de repente, ou seja, de forma traumática e de modo a impedir a satisfação do desejo, a libido do objeto é removida e a libido narcisista é retirada — pelo menos temporariamente - da parte do limite do ego que é posta em prática na percepção do objeto perdido e retorna para pontos anteriores de fixação do sentimento do Eu.

Nas neuroses de transferência normalmente esse investimento da libido narcisista é rapidamente renovado. Contudo, nas psicoses, à medida que o sentimento corporal do $\mathrm{Eu}$ sofre variações, a sensação óbvia de todo o corpo é afetada. Assim, para Federn (1952/1979), a evidência dos limites do eu corporal deve ser mantida para que o mundo exterior e a plena percepção objetiva e subjetiva do $\mathrm{Eu}$ se mantenham evidentes.

4 "le sentiment du moi est capable de se fixer ou de régresser à un stade antérieur aussi bien du point de vue de la qualité que de l'étendue" (Federn, 1952/1979, p. 121). 


\section{ARTIGOS}

A libido investida nos limites corporal do Eu, para o autor, é de origem sexual, já que as zonas erógenas são as primeiras regiões corporais de investimento e satisfação pulsional. Por isso, o sentimento corporal do Eu não é uniforme, sofre variações de acordo com sua fonte e composição.

Podemos supor, portanto, que ao ter o desejo frustrado pela perda do objeto, o psicótico regride ao estágio do sentimento de $\mathrm{Eu}$ e de desenvolvimento pulsional no qual o objeto não existia como objeto de desejo, ou seja, ao momento em que lhe era indiferente e que a pulsão não havia sido investida.

Desse modo, percebemos que, para o autor, não é a realidade que perde seu investimento, ou seu interesse, mas os limites do Eu em contato com ela, o que a torna não real, não amigável, não familiar, não existente e não viva.

Podemos concluir que, ao analisar as psicoses, Federn (1952/1979) as localiza no âmbito das falhas do Eu, que para se defender do excesso de excitação da libido objetal insatisfeita desinveste seus próprios limites, não quaisquer limites, mas precisamente os que mantinham contato com a alteridade.

Federn identifica, portanto, no desinvestimento do Eu e, com ele, na desintegração ou, ainda, na despersonalização, os sintomas iniciais. Além disso, como mais uma oposição à teoria freudiana, ele defende que "a psicose não é uma defesa, mas uma derrota. É a derrota de um eu que deixou de poder se defender contra o impacto das exigências pulsionais, as necessidades da realidade externa e os conflitos que dela decorrem" (pp. 363-364). ${ }^{5}$

Esse fracasso, nos casos de esquizofrenia, se apresenta por meio de quatro manifestações: criação de uma realidade falsa; regressão a estados anteriores, ou seja, infantis do Eu; incapacidade do pensamento abstrato, e emergência do material inconsciente (Federn, 1952/1979).

$\mathrm{O}$ inconsciente, nesses casos, encontra-se dominante no funcionamento psíquico, posto que as defesas do Eu já não funcionam. E a partir

5 'psychose elle-même n'est pas une défense mais une défaite. C'est la défaite d'un moi qui a cessé d'être capable de se défendre contre l'impact des exigences pulsionnelles, les nécessités de la réalité extérieure, et les conflits qui en dérivent" (Federn, 1952/1979, pp. 363-364). 
dessa condição psíquica, o autor propõe que a utilização da técnica psicanalítica no tratamento dos psicóticos deve se pautar não na interpretação do material inconscientes, mas sim no seu recalcamento. A intervenção do analista deve se dar junto aos aspectos psíquicos saudáveis apresentados por eles.

Assim, é a mesma alteridade que frustra e impede a satisfação pulsional, e com isso o desinvestimento dos limites do eu que investem a realidade e o objeto, que, por meio da transferência, deve auxiliar no recalcamento e no reinvestimento dos limites do eu e, consequentemente, no seu fortalecimento. Também aqui, assim como em Freud, a necessidade de cura garante o retorno da importância e centralidade da alteridade nas psicoses.

A partir desta breve exposição da teorização de Freud, Tausk e Federn sobre as psicoses, podemos concluir que a alteridade concreta se fez e se faz presente no psiquismo psicótico. Para Freud, inicialmente ela é fonte de frustração e conflito e, posteriormente, recursos para cura. Em Tausk se apresenta como fonte de excitação do desejo proibido e, portanto, causadora do conflito e perseguidora. Já para Federn, a alteridade é responsável pelo desenvolvimento do Eu e ampliação de suas fronteiras, pelo desinvestimento dessas mesmas fronteiras diante da frustração do desejo, e, ainda, pelo restabelecimento dos limites necessários ao processo de cura ou melhoras dos sintomas.

\section{Referências}

Federn, P. (1979). La psychologie du moi et les psychoses. (A. Lewis-Loubignac, trad.). Paris, France: PUF. (Trabalho original publicado em 1952).

Freud, S. (2010a). Introdução ao narcisismo. In Obras Completas (vol. XII, pp. 9-37; P. C. de Souza, trad.). São Paulo, SP: Companhia das Letras. (Trabalho original publicado em 1914).

Freud, S. (2010b). O inconsciente. In Obras Completas (vol. X, pp. 74-114; P. C. de Souza, trad.). São Paulo, SP: Companhia das Letras. (Trabalho original publicado em 1915).

Freud, S. (2010c). Neurose e psicose. In Obras Completas (vol. XVI, pp. 158-164; P. C. de Souza, trad.). São Paulo, SP: Companhia das Letras. (Trabalho original publicado em 1924).

Freud, S. (2010d). A perda da realidade na neurose e na psicose. In Obras Completas 


\section{ARTIGOS}

(vol. XVI, pp. 193-199; P. C. de Souza, trad.). São Paulo, SP: Companhia das Letras. (Trabalho original publicado em 1924).

Freud, S. (2015). Observações psicanalíticas sobre um caso de paranoia (Dementia Paranoides) Relatado em Autobiografia. In Obras Completas (vol. 10, pp. 9-80; P. C. de Souza, trad.). São Paulo, SP: Companhia das Letras. (Trabalho original publicado em 1911).

Laplanche, J., \& Pontalis, J.-B. (1988). Vocabulário da psicanálise. São Paulo, SP: Martins Fontes. (Trabalho original original publicado em 1967).

Penot, B. Verbete rejeição. In Mijolla, A. (Org.) (2005). Dicionário internacional da psicanálise. Rio de Janeiro, RJ: Imago.

Simanke, R. T. (2009). A formação da teoria freudiana das psicoses. São Paulo, SP: Edições Loyola.

Tausk, V. (1990). Da Gênese do "Aparelho de Influenciar" no Curso da Esquizofrenia. In J. Birman (Org.), Tausk e o aparelho de influenciar na psicose (pp. 37-77). São Paulo, SP: Escuta. (Trabalho original publicado em 1919).

\section{Resumos}

(Narcissism and the relation to otherness in psychoses from the points of view of Freud, Tausk and Federn)

This paper analyzes the relation or place of otherness in the psychic dynamics of psychosis based on Freud's ideas, especially those that are related to the concept of narcissism and that influenced the theories developed by Tausk and Federn, authors who ventured in the field of study and treatment of psychosis at a time when the very father of psychoanalysis declared that this was not feasible. We conclude that the concrete otherness occurred and is present in the psychotic psyche according to the three authors, so that the conflict and the therapeutic process imply the existence and the relationship with the other.

Key words: Psychoanalysis, psychosis, narcissism, otherness

(Le narcissisme et le rapport à l'altérité chez les psychoses selon Freud, Tausk et Federn)

Cet article vise à analyser le rapport ou le lieu de l'altération dans la dynamique psychique de la psychose à partir des idées de Freud, en particulier celles liées à la notion de narcissisme et qui ont influencé les théories de Tausk et Federn, auteurs qui se sont aventurés dans le domaine de l'étude et le traitement de la psychose alors que le père même de la psychanalyse jugeait cela irréalisable. Nous concluons que l'altérité 
concrète s'est opérée et est présente dans la psyché psychotique selon les trois auteurs, de sorte que le conflit et le processus thérapeutique impliquent l'existence et le rapport avec l'autre.

Mots clés: Psychanalyse, psychose, narcissisme, altérité

(El narcisismo y la relación con la alteridad en las psicosis bajo las miradas de Freud, Tausk y Federn)

Este artículo pretende analizar la relación o el lugar de la alteridad en la dinámica psíquica de la psicosis a partir de las ideas de Freud, especialmente de aquellas vinculadas al concepto de narcicismo, y que influenciaron a las de Tausk y Federn, autores que se aventuraron en el campo del estudio y del tratamiento de la psicosis en un momento en el que el propio padre del psicoanálisis decía que era imposible. A partir de este estudio, podemos concluir que, para los tres autores, la alteridad concreta se hizo y se hace presente en la psique psicótica, de forma que el conflicto y el proceso terapéutico implican la existencia y la relación con el otro.

Palabras clave: Psicoanálisis, psicosis, narcisismo, alteridad

(Narzissmus und das Verhältnis zur Alterität bei Psychosen aus der Perspektive Freuds, Tauks und Federns)

Diese Arbeit analysiert die Beziehung oder den Ort der Alterität in der psychischen Dynamik der Psychose, basierend auf Freuds Ideen, die mit dem Konzept des Narzissmus in Verbindung stehen und die Tausk und Federn beeinflusst haben. Diese Autoren haben sich in den Bereich der Studie und Behandlung von Psychosen gewagt und zwar zu einer Zeit, als der Vater der Psychoanalyse behauptete, dass dies ein unmögliches Unterfangen sei. Aus unserer Studie schließen wir, dass die konkrete Alterität in der psychotischen Psyche gemäß diesen Autoren vorhanden ist, so dass der therapeutische Konflikt und Prozess die Existenz des Andern und die Beziehung mit ihm einschließen.

Schlüsselwörter: Psychoanalyse, Psychose, Narzissmus, Alterität

Citação/Citation: Marini, S., \& Martinez, V. C. V. (2019, junho). O narcisismo e a relação com a alteridade nas psicoses sob os olhares de Freud, Tausk e Federn. Revista Latinoamericana de Psicopatologia Fundamental, 22(2), 298-313. http://dx.doi.org/10.1590/ 1415-4714.2019v22n2p298.8

Editoras/Editors: Profa. Dra. Ana Maria G. R. Oda e Profa. Dra. Sonia Leite 


\section{ARTIGOS}

Submetido/Submitted: 30.12.2018 / 12.30.2018 Revisado/Revised: 12.3.2019/ 3.12.2019

Aceito/Accepted: 20.3.2019/3.20.2019

Copyright: (C) 2009 Associação Universitária de Pesquisa em Psicopatologia Fundamental/ University Association for Research in Fundamental Psychopathology. Este é um artigo de livre acesso, que permite uso irrestrito, distribuição e reprodução em qualquer meio, desde que o autor e a fonte sejam citados / This is an open-access article, which permits unrestricted use, distribution, and reproduction in any medium, provided the original authors and sources are credited.

Financiamento/Funding: Este trabalho não recebeu financiamento / This work received no funding.

Conflito de interesses/Conflict of interest: As autoras declaram que não há conflito de interesses / The authors declare that there is no conflict of interest.

\section{Silvia Marini}

Doutoranda pelo Programa de Pós-Graduação em Psicologia da Universidade Estadual de Maringá (Maringá, PR, Br), na linha de pesquisa Psicanálise e Civilização; bolsista CAPES; pesquisadora do Laboratório de Estudos e Pesquisa em Psicanálise e Civilização da Universidade Estadual de Maringá; docente do Centro Universitário Metropolitano de Maringá - UNIFAMMA (Maringá, PR, Br), e da Faculdade de Tecnologia e Ciências do Norte do Paraná - UNIFATECIE (Paranavaí, PR, Br).

Av. Colombo, 5790, bl $10-$ Zona 7

87020-900 Maringá, PR, Br

http://orcid.org/0000-0001-6087-834X

silviamarini.psico@gmail.com.

\section{Viviana Carola Velasco Martinez}

Professora doutora não titular da Universidade Estadual de Maringá (Maringá, PR, Br) na graduação e no programa de Pós-Graduação em Psicologia, na linha de pesquisa Psicanálise e Civilização; coordenadora e pesquisadora do Laboratório de Estudos e Pesquisa em Psicanálise e Civilização da mesma universidade.

Av. Colombo, 5790, bl $10-$ Zona 7

87020-900 Maringá, PR, Br

http://orcid.org/0000-0002-5389-7988

vcvmartinez@hotmail.com.

This is an open-access article, which permits unrestricted use, distribution, BY-NC and reproduction in any medium for non-commercial purposes provided the original authors and sources are credited. 